\title{
Optimizing ANN performance using DOE: application on turning of a titanium alloy
}

\author{
John Kechagias ${ }^{1, *}$, Aristidis Tsiolikas ${ }^{1}$, Panagiotis Asteris ${ }^{2}$ and Nikolaos Vaxevanidis ${ }^{3}$ \\ ${ }^{1}$ Department of Mechanical Engineering, Technological Educational Institute of Thessaly, GR 41110, \\ Larissa, Greece \\ ${ }^{2}$ Department of Civil Engineering Educators, School of Pedagogical and Technological Education, \\ GR 14121, N. Heraklion Attikis, Greece \\ ${ }^{3}$ Department of Mechanical Engineering Educators, School of Pedagogical and Technological \\ Education, GR 14121, N. Heraklion Attikis, Greece
}

\begin{abstract}
A methodology is presented to optimize the performance of an Artificial Neural Network (ANN) using Design of Experiments (DOE). 8 different feed forward back propagation (FFBP) ANNs were developed and tested according to the L8 full factorial orthogonal array. The 3 parameters tested were: Number of Hidden Neurons, Learning rate, and Momentum; each one having two levels. By utilizing the analysis of means (ANOM) and the analysis of variances (ANOVA), the optimum levels of ANN parameters were determined. The developed ANN was applied for predicting cutting forces and average surface roughness in turning Ti-6Al-4V alloy.
\end{abstract}

\section{Introduction}

Nowadays Artificial Neural Network (ANN) modeling is used frequently for the prediction of machinability parameters on all of the precision machining processes [1]. Typically, a feed forward back propagation ANN (FFBP ANN) with one hidden layer is appropriate for precision machining process quality indicators prediction. In general, ANNs are robust computing modules are used to model complex relationships which are difficult to be described through physical models. ANNs have been extensively applied to model various machining operations; either conventional or non-conventional [2]. ANN applications in engineering are numerous and the review of them is beyond the scope of the present research.

ANN is a network of many simple processing units (also called nodes or neurons) each with a small amount of local memory and in some cases arranged in layers. Nodes are connected through communication channels (connection weights). Connections bear encoded arithmetic data. Nodes process only local data and inputs brought to them through the connections. From a scientific point of view, ANNs are systems consisting of a number of processing units or elements that calculate in parallel and whose functioning is determined by the network structure, the connection weights and the processing that is carried out on the elements or the nodes [3]. These systems tend to store empirical knowledge and to make it

\footnotetext{
*Corresponding author: jkechag@teilar.gr
} 
available for use similarly to the human brain. Knowledge is acquired through learning and it is stored in the connections between neurons [4].

Formulation of ANNs is the mathematical modeling of the biological neuron networks, so that they can perform complex and intelligent calculations similar to the ones performed by the human brain. Most ANN types require a training stage, during which connection weights are adapted regarding a set of training data. Hence, ANNs learn or are trained by examples. When trained properly, ANNs can generalize (e.g. predict output values) beyond the field of training data. Training algorithms commonly implemented are Gauss-Newton, Levenberg-Marquardt, conjugate-gradients algorithms, etc. ANNs can operate on parallel computer systems, since calculations on nodes are highly independent to each other.

In general, a large number of ANN types have been proposed for engineering applications. In the field of machining, the most commonly used types are the Multilayer Perceptrons (MLP) and the Radial Basis Function networks (RBF), which belong to the Supervised learning - Feed forward ANN category and Self-Organizing Maps (SOM) that belongs to the Unsupervised learning - Competitive ANN category $[2,5]$.

In this study in order to investigate the effects of learning and architecture parameters on neural network performance, full factorial design was implemented. Learning rate and momentum constant were used as learning parameters of the neural network, whilst the number of neurons in hidden layer was treated as architectural parameter. An orthogonal array $\mathrm{L}_{8}$ is used for the construction of the 8 different ANNs. ANOM and ANOVA were applied to the ANNs performance and the optimum architecture and learning parameters were obtained. The optimum ANN is capable of estimating/predicting main cutting force $(\mathrm{Fc})$ and surface quality $(\mathrm{Ra})$ during longitudinal turning of Ti6Al4V ELI titanium alloy.

\section{Turning process and measurements}

Turning experiments were conducted on a Kern Modell D18L conventional lathe. The kinematics of the longitudinal turning process is illustrated in Figure 1(a). A 3D cutting force system was considered according to the theory of oblique cutting [6]; see also Figure 1(b).

Test material was titanium alloy Ti-6Al-4V ELI; an Alpha-Beta titanium alloy which contains $6 \%$ alpha stabilizer (aluminium) and $4 \%$ beta stabilizer (vanadium) by weight. Its hardness is $326 \mathrm{HB}$. It is very similar to Ti-6Al-4V (Grade 5), with the difference that Ti$6 \mathrm{Al}-4 \mathrm{~V}$ ELI contains reduced oxygen nitrogen, carbon and iron levels [7]. Test specimens were supplied in the form of $\varnothing 45 \mathrm{~mm}$ bars.

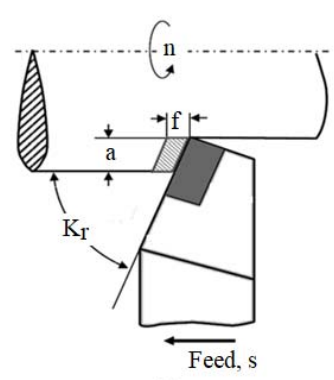

(a)

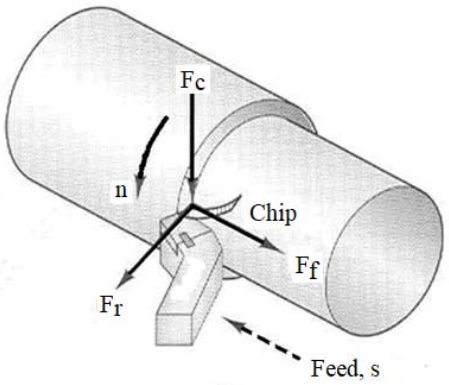

(b)

Fig. 1. (a) Kinematics of the turning process and (b) Three-dimensional cutting force system.

The surface texture analysis was performed by using a Rank Taylor-Hobson ${ }^{\circledR}$ Surtronic $3+$ profilometer equipped with the Talyprof $^{\circledR}$ software. A three-axis piezoelectric dynamometer Kistler $^{\circledR}$ type $9257 \mathrm{~B}$ was used for the cutting forces measurements. During 
machining, tool wear was maintained within the limit as per ISO specification and no cutting fluid was used; experimental procedure was described in details in Ref. [2].

The experimental procedure was designed using full factorial Taguchi method [8], which uses an orthogonal array to study the entire parametric space with performing only a limited number of experiments. For each material, the main cutting parameters (rotational speed - $\mathrm{n}$, $\mathrm{rpm}$, feed rate - $\mathrm{f}, \mathrm{mm} / \mathrm{rev}$ and depth of cut - a, $\mathrm{mm}$ ) were assigned on a standard L27 Orthogonal Array (OA). Three levels were specified for each of the three cutting parameters. Table 1 summarizes the experimental results and the final matrix for the ANN implementation as it is explained in a next section.

Table 1. Taguchi L27 Orthogonal Array.

\begin{tabular}{|c|c|c|c|c|c|c|c|}
\hline $\begin{array}{c}\text { No of } \\
\text { Experiment }\end{array}$ & $\begin{array}{l}\text { Spindle } \\
\text { speed: } \mathrm{n} \\
\text { (rpm) }\end{array}$ & $\begin{array}{c}\text { Feed rate: } \mathrm{f} \\
(\mathrm{mm} / \mathrm{rev})\end{array}$ & $\begin{array}{l}\text { Depth } \\
\text { of cut: } \\
\text { a (mm) }\end{array}$ & $\begin{array}{l}\mathrm{Fc} \\
(\mathrm{N})\end{array}$ & $\begin{array}{c}\mathrm{Ra} \\
(\mu \mathrm{m})\end{array}$ & $\begin{array}{c}-10 \log \\
(\mathrm{Fc})\end{array}$ & $\begin{array}{c}-10 \log \\
(\mathrm{Ra})\end{array}$ \\
\hline 1 & 850 & 0.1 & 0.5 & 132 & 1.4 & -21.2 & -1.46 \\
\hline 2 & 850 & 0.1 & 1 & 240 & 1.6 & -23.8 & -2.04 \\
\hline 3 & 850 & 0.1 & 1.5 & 330 & 1.42 & -25.1 & -1.52 \\
\hline 4 & 850 & 0.18 & 0.5 & 200 & 1.27 & -23 & -1.03 \\
\hline 5 & 850 & 0.18 & 1 & 352 & 1.67 & -25.4 & -2.22 \\
\hline 6 & 850 & 0.18 & 1.5 & 500 & 2.6 & -26.9 & -4.14 \\
\hline 7 & 850 & 0.33 & 0.5 & 288 & 6.93 & -24.5 & -8.4 \\
\hline 8 & 850 & 0.33 & 1 & 562 & 12.47 & -27.4 & -10.9 \\
\hline 9 & 850 & 0.33 & 1.5 & 800 & 14.73 & -29 & -11.6 \\
\hline 10 & 600 & 0.1 & 0.5 & 120 & 10.93 & -20.7 & -10.3 \\
\hline 11 & 600 & 0.1 & 1 & 226 & 11.37 & -23.5 & -10.5 \\
\hline 12 & 600 & 0.1 & 1.5 & 318 & 6.49 & -25 & -8.12 \\
\hline 13 & 600 & 0.18 & 0.5 & 182 & 2.99 & -22.6 & -4.75 \\
\hline 14 & 600 & 0.18 & 1 & 350 & 2.55 & -25.4 & -4.06 \\
\hline 15 & 600 & 0.18 & 1.5 & 502 & 3.96 & -27 & -5.97 \\
\hline 16 & 600 & 0.33 & 0.5 & 270 & 9.2 & -24.3 & -9.63 \\
\hline 17 & 600 & 0.33 & 1 & 538 & 8.93 & -27.3 & -9.5 \\
\hline 18 & 600 & 0.33 & 1.5 & 760 & 9.2 & -28.8 & -9.63 \\
\hline 19 & 420 & 0.1 & 0.5 & 140 & 2.19 & -21.4 & -3.4 \\
\hline 20 & 420 & 0.1 & 1 & 258 & 2.19 & -24.1 & -3.4 \\
\hline 21 & 420 & 0.1 & 1.5 & 370 & 2.21 & -25.6 & -3.44 \\
\hline 22 & 420 & 0.18 & 0.5 & 236 & 2.72 & -23.7 & -4.34 \\
\hline 23 & 420 & 0.18 & 1 & 410 & 3.45 & -26.1 & -5.37 \\
\hline 24 & 420 & 0.18 & 1.5 & 570 & 3.62 & -27.5 & -5.58 \\
\hline 25 & 420 & 0.33 & 0.5 & 284 & 8.34 & -24.5 & -9.21 \\
\hline 26 & 420 & 0.33 & 1 & 564 & 8.17 & -27.5 & -9.12 \\
\hline 27 & 420 & 0.33 & 1.5 & 840 & 7.95 & -29.2 & -9 \\
\hline \multicolumn{4}{|c|}{ Mean value } & 383 & 5.57 & -25.2 & -6.24 \\
\hline
\end{tabular}

\section{Neural network modelling}

In this study, artificial neural networks were used to model the turning process and to predict cutting forces and surface roughness of the machined specimens. The experimental data of Table 1 were presented in the network by using the MATLAB ${ }^{\circledR}$ R2014b program, and were randomly separated to train $(70 \%)$, validation $(15 \%)$ and test $(15 \%)$ data. A multilayer feed forward neural network (FF-NN) was trained under supervised learning using the back- 
propagation algorithm. Gradient descent with momentum (traingdm) was used as the training function and mean squared error (MSE) as the performance function, while (learngdm) was selected as adaption learning function. Hyperbolic tangent sigmoid and a linear transfer function were applied in hidden and output layer, respectively.

The input vectors of the feed forward ANN were presented to input neurons and then they were processed by the computational neurons of hidden and output layers, respectively. A comparison between network output values and target values estimates the error of the neural network. During the learning process, error is minimized by adjusting of the weights $[2,4]$.

The signal factors (input parameters) of the turning process, namely the spindle speed, feed rate and depth of cut consists the three neurons of the input layer, while cutting force $(\mathrm{Fc})$ and average surface roughness $(\mathrm{Ra})$ represent the output neurons.

In order to investigate the effects of learning and architecture parameters on neural network performance, full factorial parameter design was implemented. Learning rate and momentum constant were used as learning parameters of the neural network, whilst the number of neurons in hidden layer was treated as architectural parameter; see also Ref. [9].

Each one of the above factors consists of two levels, therefore an $\mathrm{L}_{8}\left(2^{3}\right)$ orthogonal array was selected and eight different neural networks were created and tested, according to Table 2; the results obtained are summarized in Table 3.

Table 2. Neural network parameter design.

\begin{tabular}{|c|c|c|c|}
\hline & Neural Network Parameters & \multicolumn{2}{|c|}{ Levels } \\
\hline A & Number of neurons in hidden layer & 4 & 8 \\
\hline B & Learning rate & 0.001 & 0.01 \\
\hline C & Momentum & 0.4 & 0.8 \\
\hline
\end{tabular}

Table 3. Full factorial design and the results of tested ANNs.

\begin{tabular}{|c|c|c|c|c|c|}
\hline a/a & $\begin{array}{c}\text { Num. of neurons } \\
\text { in hid. layer }\end{array}$ & $\begin{array}{c}\text { Learning } \\
\text { rate }\end{array}$ & Momentum & $\begin{array}{c}\text { MSE } \\
\text { validate }\end{array}$ & $\begin{array}{c}\text { Regression: } \\
\text { (RALL) }\end{array}$ \\
\hline 1 & 4 & 0.001 & 0.4 & 0.43727 & 0.97296 \\
\hline 2 & 8 & 0.001 & 0.4 & 3.5896 & 0.97807 \\
\hline 3 & 4 & 0.01 & 0.4 & 0.76281 & 0.99024 \\
\hline 4 & 8 & 0.01 & 0.4 & 5.5581 & 0.98317 \\
\hline 5 & 4 & 0.001 & 0.8 & 1.0126 & 0.9831 \\
\hline 6 & 8 & 0.001 & 0.8 & 4.4529 & 0.98428 \\
\hline 7 & 4 & 0.01 & 0.8 & 3.134 & 0.97744 \\
\hline 8 & 8 & 0.01 & 0.8 & 5.9889 & 0.95735 \\
\hline
\end{tabular}

It can be observed from the results of Table 3, that the minimum mean squared error (MSE) of validation data was obtained when the number of hidden neurons was set in level one, i.e., 4; learning rate on level one, i.e., 0.001 and momentum constant on level one, i.e., 0.4. Note also that most of the tested ANNs presented very good correlation between the actual and predicted values, according to the regression plots.

Due to the application of the Taguchi method in the experimental design, signal to noise ratios, $\eta(\mathrm{db})$ were calculated for the obtained results. For the mean squared error (MSE) of the ANNs the lower possible values are desirable; when the value is equal to zero, it means that there is no error $[2,9]$. Therefore, "the smaller the better" $(\mathrm{S} / \mathrm{N})$ ratio was selected, according to the Taguchi method and was calculated by using the equation given below [10]:

$$
\eta=-10 \log _{10}\left[\frac{1}{n} \sum_{i=1}^{n} y_{i}^{2}\right](d b)
$$

Where $\mathrm{y}_{\mathrm{i}}$ is the data from the experiments at the $\mathrm{i}^{\text {th }}$ trial and $n$ is the number of trials. 


\section{Statistical analysis of the results}

Next, statistical analysis of the computational results of Table 3 was performed, so as to optimize the parameters of the neural network. Analysis of means (ANOM); see Table 4 and analysis of variances (ANOVA); see Table 5 were used for this purpose. By conducting analysis of means, an estimation of the effect of each factor can be performed by using the $\mathrm{S} / \mathrm{N}$ ratio, i.e., $\eta \mathrm{MSE}(\mathrm{db})$ values of the results. In general, the optimum level of a parameter is the level that has the highest value of $\eta(\mathrm{db})$ [10]. According to the ANOM diagram in Figure 2, the optimum level for all the parameters is the first level.

Table 4. Analysis of means (ANOM).

\begin{tabular}{|c|c|c|}
\hline & Level 1 & Level 2 \\
\hline Num of neurons in hidden layer & 1.33667 & 4.89738 \\
\hline Learning rate & 2.37309 & 3.86095 \\
\hline Momentum & 2.58694 & 3.6471 \\
\hline
\end{tabular}

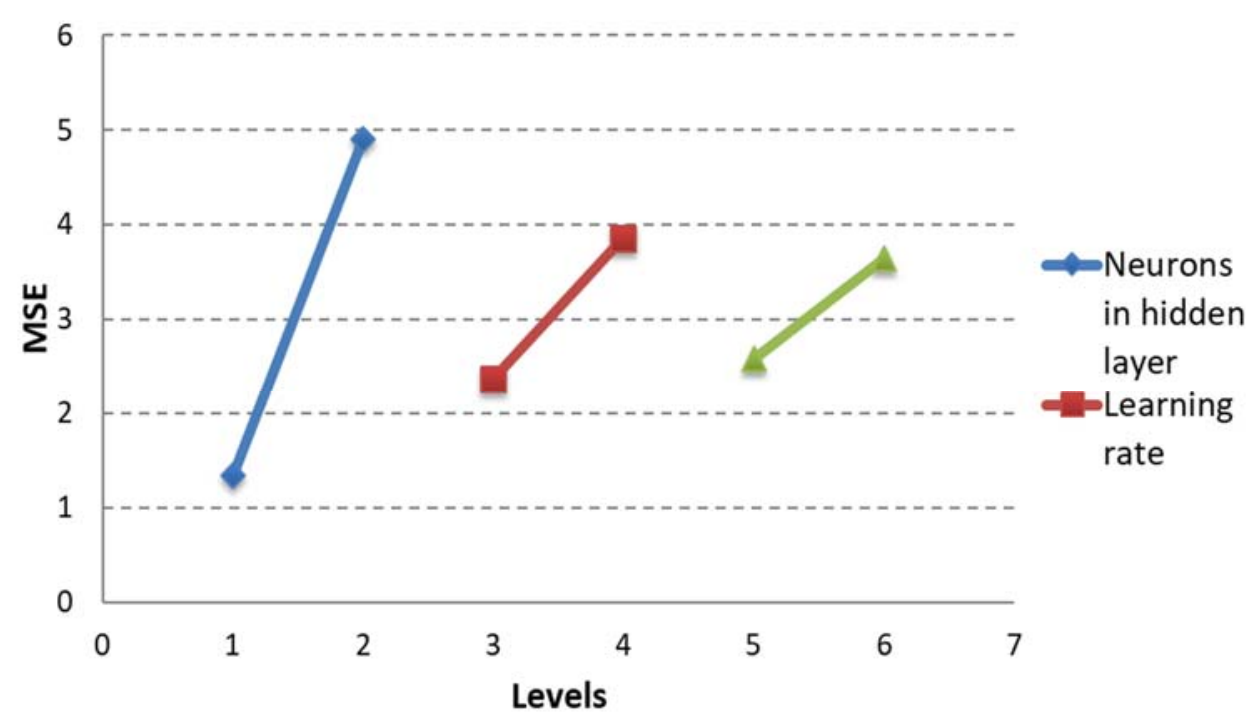

Fig. 2. ANOM diagram for $\eta_{\mathrm{MSE}}(\mathrm{db})$.

The most significant factor according to analysis of variance is the Number of neurons (76\%). The other two parameters, learning rate and momentum constant have a significance influence of about $13 \%$ and $7 \%$ respectively; see Table 5 .

Table 5. Analysis of variance (ANOVA).

\begin{tabular}{|c|c|c|c|c|c|c|}
\hline & DoF & SoS & MS & F & P-value & Contribution (\%) \\
\hline $\begin{array}{c}\text { Number of neurons } \\
\text { in hidden layer }\end{array}$ & 1 & 25.3572 & 25.3572 & 76.02 & 0.001 & 75.995 \\
\hline Learning rate & 1 & 4.4275 & 4.4275 & 13.27 & 0.0219 & 13.269 \\
\hline Momentum constant & 1 & 2.2479 & 2.2479 & 6.74 & 0.0603 & 6.736 \\
\hline Total & 3 & 32.0326 & & & & \\
\hline Error & 4 & 1.3342 & 0.3335 & & & \\
\hline Total Error & 7 & 33.3667 & 4.7666 & & & \\
\hline
\end{tabular}




\section{Conclusions}

The choice of the most suitable ANN settings is a very difficult task that depends on many variables; for the time being, a standard procedure does not exist.

Therefore, the trial and error method is the most commonly used procedure to identify the best settings.

The main disadvantage of this method is that it requires a lot of trials to be made and as a result it is time consuming. In order to avoid the above drawback, optimization of the architecture and the training parameters of the neural network were attempted, by applying the DOE method.

The parameters studied were the number of hidden neurons, learning rate and momentum constant, while mean squared error of the network was used as the performance indicator. To each one of the parameters there were assigned two levels; therefore, eight combinations of ANNs were tested.

The results of this paper indicate that the most significant factor is the number of neurons in hidden layer, which has the highest percentage of contribution (76\%).

Moreover, according to the ANOM diagram, the minimum mean squared error can be achieved when the three parameters are set at the lowest level.

For a future work, note, that this methodology can be tested in other manufacturing processes and for different ANNs parameters.

\section{References}

1. M. Chandrasekaran, M. Muralidhar, C.M. Krishna, U.S. Dixit, Int. J. of Adv. Manu. Tech., 46 (5-8) 445-464 (2010)

2. N.M. Vaxevanidis, J. Kechagias, N.A. Fountas. D.E. Manolakos, The Open Cons. and Building Tech. J., 8 (1) 389-399 (2015)

3. O.S. Eluyode, D.T. Akomolafe, European Journal of Applied Engineering and Scientific Research, 2 (1) 36-46 (2013)

4. S. Haykin, Neural networks, a comprehensive foundation (NJ, Prentice Hall. 1999)

5. A.K. Jain, J. Mao, K.M. Mohiuddin, IEEE Computer, 29 (3), 31-44 (1996)

6. G. Boothroyd, W. Knight, Fundamentals of Machining and Machine Tools (CRC Press. 2005)

7. P.J. Arrazola, A. Garay, L.M. Iriarte, M. Armendia, S. Marya, F. Le Maitre, J. Mat. Proc. Tec. 209, 2223-2230 (2009)

8. R.K. Roy, A primer on the Taguchi method, (Society of Manufacturing Engineers. 2010).

9. J. Kechagias, P. Kyratsis and N. Mastorakis, Recent Adv. on Mechanics, Materials, Mechanical Eng. Chem. Eng., 1 98-107 ( 2015)

10. M.S. Phadke, Quality Engineering using Robust Design (Prentice-Hall, Englewood Cliffs, NJ, 1989) 